\title{
Osmotic pressure in the fermentation media technologies
}

\section{Anatolii Sokolenko, Oleksandr Shevchenko, Iryna Makcymenko, Inna Vinnichenko, Volodumyr Kostyuk}

\author{
National University of food Technologies, Kyiv, Ukraine
}

\section{Keywords:}

Fermentation

Pressure

Glucose

Ethanol

\section{Article history:}

Received 8.03.2017

Received in revised

form 29.01.2017

Accepted 30.03.2017

\section{Corresponding author:}

Oleksandr

Shevchenko

E-mail:

Tmipt@ukr.net

DOI:

$10.24263 / 2304-$

974X-2017-6-1-15

\section{Abstract}

Introduction. It was conducted the research for creating the physical and mathematical formalization of the changes in the chemical composition of the environment, its energy potential and osmotic pressures.

Materials and methods of a research is defined on the basis of the purposes and problems of theoretical searches, excluded need of physical materials' usage, and as the basis of researches were used the known regularities of anaerobic processes of fermentation and phenomenological reasons with approaching to the provisions of thermodynamics.

Result and discussion. It is considered the use of biochemical activity of microorganisms in the fermentative productions in which input supply streams are transformed with destructive influences and formation of substances with various molecular masses. Such processes can be considered self-flowing and irreversible that means the presence of entropy losses in the form of thermal energy. At the same time the destructive influences accompanied by formation of substances with a smaller molecular masses that leads to increase of osmotic pressure in cultural environments. Critical value achievement of the last ones stops the further biochemical transformations with the achievement of bacteriostatic and even fatal outcome on microflora. Energy ensuring of these processes is reached due to the chemical energy of high-molecular connections of input material streams.

Transition from solutions with accurately designated structure to environments of food and microbiological industries means the essential complication during osmotic pressure determining. It is explained, firstly, by continuous dynamics of change in environments' structure and, secondly, the presence of set of substances of transition processes. It is offered to use in the determination of osmotic pressure of the superposition principle. The basis for such position is well-known information that all transformations and synthesis of intermediate substances happen at the level of endogenous processes in yeast cells. Also, it is noted the efficiency of process organization of biological system functioning from constancy of environments' indicators with taking into account the external influences and the importance of the directions of osmotic molecular diffusion. Colligative properties of solutions in cultural environments change in proportion to the molality of the dissolved substance.

Conclusion. The osmotic pressure of the substances' solutions, which are formed as a result of chemical and biochemical reactions are proportional to the equalizing coefficients in the corresponding equations, and changes of osmotic pressure before and after the chemical and biochemical reactions are defined by changes of the number of molecular structures, which are formed. 


\section{— Processes and Equipment of Food Productions -}

\section{Introduction}

Biochemical activity of microorganisms is used in technologies, related to production of bread, milk products, wine, alcohol, vinegar, pickled or marinated vegetables, beer, amino acid, enzyme preparations, antibiotics, dietary proteins, etc $[1,12,14]$. The incoming supply streams with their organically structure are transformed upon destructive influence of microorganisms to their components with formation of substances with different and, often, smaller molecular mass $[2,8,10]$. In such cases an increasing of osmotic pressure of solutions, in which those changes are in process, are expected $[8,10,13]$.

Microbiological provision, that is required for transformation behavior of a material flow, can result in critical values of transformations, whereby the microorganisms of the environment cause bacteriostatic effects. An example for this is a fermentation of sugarcontaining substances with alcohol accumulation in the brew of $10-12 \%$, and the yeasts have to be extracted from the beer after fermentation.

Modern technical possibilities allow to guaranteed reach the bacteriostatic conditions in separate processes, but the special conditions of the following processes can neutralize them, for example, because of microbial flora of packing materials, package, environment [1]. Upon such conditions, when selecting a technology, such methods, upon which the environments themselves or final products ensure an "aseptically protection" shall prevail, for example, by high osmotic pressures (molasses, juice concentrates, beer must, honey). Thereat, the important role belongs to possibilities of non-stop control of osmotic pressures.

Research objective. In connection with mentioned above, the physical and mathematical formalization of definitions of the osmotic pressures is specified.

\section{Materials and methods}

The object of researchs is the technology of anaerobic fermentation. It were researched the parameters of culture medium, the influences and interaction of physical and chemical factors in the biochemical synthesis of ethanol.

As the basis of researches were used the known regularities of anaerobic processes of fermentation and phenomenological reasons with approaching to the provisions of thermodynamics $[8,10]$.

The physical and mathematical formalization of definitions of the osmotic pressures in the fermentation media technologies was determined basing on detailed analysis of physical and chemical principles and effects of osmotic pressure of environments colligative properties [1-14].

For calculating of the values of the osmotic pressure it was used the principle of superposition, the laws of Gay-Lussac [4, 9], equivalent weights and Van't Hoff [6, 7, 11], taking into account the fact that the nature of the osmotic pressure is defined by the formations at the molecular level.

As the basis for studying of effects on biological objects it was used the experience of solutions estimates taking into account the the concept of the systems stationary state $[1,2$, $4,8,10,16,18]$. 


\section{Result and discussion}

Transition from environments with defined components and concentrations of dry substances (DS) to the food technologies environment means an essential increasing of difficulty level in definition of osmotic pressures. Even in cases of clear definition of concentrations and molecular masses of incoming flow and final result of their transformation, this questions remains open, taking into account the fact that the transition itself is accompanied by synthesis and presence of transitional processes substances. It's obvious, that in such cases the principle of superposition would be useful, but only upon conditions of known chemical and concentric composition. However, in modern circumstances and upon absence of corresponding analyzers, this question remains open.

For appraisal of degree of complexity of solution of task of definition of osmotic pressure values lets consider the example of technology, in which the process of transition characteristics is clearly represented. Such example can be a wine champagnization process in its classical presentation, that consists of following stages:

- preparing of the mass-production mixture by mixing of blended wine materials with mass-production liqueur, sand sugar;

- mixing of the mass-production mixture with a blend of pure culture yeast with fining materials;

- packaging of the mass-production mixture and sealing of bottles with corks and metal brackets;

- lining of the bottles in piles in the horizontal for secondary fermentation at a temperature of $10-15^{\circ} \mathrm{C}$ and 3-year maturation;

- re-laying of bottles and blending of environments for finishing of biochemical changes processes.

Corresponding to demands of microbiological provision, there are from 5 to 50 billions of yeast cells, that equals the level under $20 \mathrm{~m}^{2}$ of square of mass exchange of cells with the environment.

The biochemical process of wine maturation divides to 4 periods:

1. Active fermentation, multiplication and increasing of biomass (up to 15 days);

2. Death of cells and transition of ferments and biologically active substances to the environment of the bottle (up to 100 days);

3. Active evolvement of fermentation processes (up to 350 days);

4. Inactivation of the ferments and fading of all biochemical process.

From the perspective of interests of definition of dynamic of osmotic processes, a special meaning has the transition in the substances transformation. The main components of osmotic pressures at starting of the process are represented by occurrence of sugar and alcohol. Hereby the concentration of the sugar is calculated in such a way as to possibly receive a final concentration of $\mathrm{CO}_{2}$ in the wine at a rate of $10 \mathrm{~g} / \mathrm{l}$. The osmotic pressure of the dissolved sugar is accompanied by the osmotic pressure of the ethyl alcohol. Results of the biochemical transformation are represented by a correlation

$$
\frac{\mathrm{C}_{6} \mathrm{H}_{12} \mathrm{O}_{6}}{180}=\frac{2 \mathrm{C}_{2} \mathrm{H}_{5} \mathrm{OH}}{92}+\frac{2 \mathrm{CO}_{2}}{88}
$$

that is accompanied with masses proportion. 


\section{- Processes and Equipment of Food Productions -}

It follows that for obtaining of concentration of carbon dioxide in the wine at the rate of $10 \mathrm{~g} / \mathrm{l}$, it's necessary to brew the glucose in an amount of

$$
m_{g l}=\frac{180 \cdot 10}{88}=20,45 \mathrm{~g}
$$

Thereat, amount of the synthesized alcohol will make

$$
m_{\mathrm{CO}_{2}}=\frac{20,45 \cdot 88}{180}=10 \mathrm{~g}
$$

Considering that the abovementioned masses of alcohol and glucose relate to 11 of wine, it means that the concentration of alcohol will increase by $1,045 \%$. With that, the mass of carbon dioxide will make:

$$
m_{\mathrm{CO}_{2}}=\frac{20,45 \cdot 88}{180}=10 \mathrm{~g}
$$

Let's define the volumes of liquid phases that correspond to the solution in proportion $1 \mathrm{~g} /$ mole of the substance:

\begin{tabular}{|l|l|l|}
\hline $11-20,45 \mathrm{~g}$ of glucose & $11-10,45 \mathrm{~g} \mathrm{C}_{2} \mathrm{H}_{5} \mathrm{OH}$ & $\begin{array}{l}11-10 \mathrm{~g} \mathrm{of} \mathrm{CO}_{2} \\
\mathrm{~V}-44 \mathrm{~g}\end{array}$ \\
\hline $\mathrm{V}-180 \mathrm{~g}$ & $V_{\text {alk }}=\frac{46}{10,45}=4,4 \pi$ & $V_{\mathrm{CO}_{2}}=\frac{44}{10}=4,4 l$ \\
\hline$V_{g l}=\frac{180}{20,45}=8,8 \pi$ & & \\
\hline
\end{tabular}

With rate of temperature $\mathrm{T}=293 \mathrm{~K}$ the osmotic pressure of the glucose at starting of the process equals:

$$
P_{\text {osm.gl. }}=\frac{R T}{V}=\frac{8,3144 \cdot 10^{3} \cdot 293 \cdot 10^{-6}}{8,8}=0,27683 \mathrm{MPa}
$$

Osmotic pressures of synthesized $\mathrm{C}_{2} \mathrm{H}_{5} \mathrm{OH}$ and carbon dioxide, respectively:

$$
\begin{gathered}
P_{\text {osm.alk. }}=\frac{R T}{V}=\frac{8,3144 \cdot 10^{3} \cdot 293 \cdot 10^{-6}}{4,4}=0,553663 \mathrm{Mpa} \\
P_{\text {osm. } \mathrm{CO}_{2}}=\frac{R T}{V}=\frac{8,3144 \cdot 10^{3} \cdot 293 \cdot 10^{-6}}{4,4}=0,553663 \mathrm{Mpa}
\end{gathered}
$$

Cumulative change of osmotic pressures of the substances in proportion

$$
\frac{P_{\text {osm.alk. }}+P_{\text {osmCO }_{2}}}{P_{\text {osm.gl. }}}=\frac{0,553663+0,553663}{0,27683}=4
$$




\section{— Processes and Equipment of Food Productions-}

means a possibility to formulate the following rule on basis of the principles of equivalence of mass and Van't Hoff law:

"Osmotic pressure of solution of substances, that interact in chemical or biochemical reactions, are directly proportional to the comparative coefficients in the corresponding formulas".

With that, it's possible to arrive at an other conclusion when evaluating results corresponding to changes of the osmotic pressure and quantity of molecules of solutes. This is because every molecule of glucose transforms to two molecules of alcohol and two molecules of carbon dioxide. It results to the other conclusion that relates to generalization of physical background of osmotic pressure phenomenon:

"Changes of osmotic pressures are directly proportional to the changes of quantities of molecular structures in solutions"

In other words, the nature of osmotic pressures is defined by formations at molecular levels.

The mentioned estimated changes of the osmotic pressures, that display champagnization processes, shall be considered at the level of the first approximation, because an unaccounted potential of molecular structures, connected with destruction of the yeast cells, evolvement of fermentation processes with a following inactivation of the ferments, takes place. It's obvious that those final occurrences of the champagnization increase the level of the osmotic pressure in the system. But theoretical possibilities, related to this additional quantity of molecular structures are practically exhausted, so further steps to the definition of the osmotic pressures have to be connected with experimental measurements.

The ground for those is the experience of the study of characteristics of the solutions at the different levels of values. Such study, in the first place, is targeted at an evaluation of their impact on biological objects. The totality of such values defines an estimated functional level of the organism, which is supported due to the activity of complexes of systems, that are responsible for performing of different functions. Corresponding to the homeostasis conception, a biological object can remain in the balanced condition only upon condition that every subsystem in its composition also is in balanced condition. Effectivity of processes of organization and functioning of living systems depends on the state of the interior environment, that has to be constantly supported with a glance to the exterior impact. For example, the key factor for the system "environment - microorganisms" during its existence is a proportion of osmotic pressures of the cultural environment $P_{\text {osm.env. }}$ and the cell cytoplasm $\mathrm{P}_{\text {osm.s. }}$. If the formula $\mathrm{P}_{\text {osm.env. }}>\mathrm{P}_{\text {osm.s }}$ is accomplished, the osmotic and molecular diffusion will be trended from the cell to the environment. In cases of rehydration of the primary product, direction of the osmotic and molecular diffusion changes to the opposite one, that corresponds with special aspects and laws of thermodynamic of biological processes. The special aspect of the latter is the irreversibility, and the balanced condition of the cell is unsuitable, cause in such a case flowing of directed processes will be impossible, except accidental variations from the balanced condition. For this very reason thermodynamics of biological processes operates with concept of stationary state of a system. In the stationary states the values don't change in course of time, but can differ in various parts of the system. In other words, in such systems there are 


\section{— Processes and Equipment of Food Productions -}

value gradients, which are constantly supported. It's possible only due to inflow of an energy or substance from outside.

In the human organism a system that is responsible for processes of absorbing, allocation and excretion of water and salts and supporting of osmotic pressure of the liquids of the interior environment is the osmoregulation system. It's main controlled value is total concentration of the osmotic active substances, that is supported with especially high accuracy. The executive organs, that are responsible for supporting of the osmotic pressures

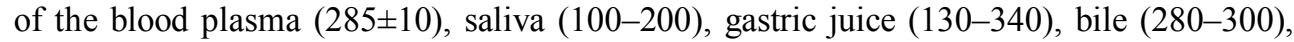
urine $\left(50-1550 \mathrm{mmol} / \mathrm{kg} \mathrm{H}_{2} \mathrm{O}\right)$ are kidneys, sudoriferous glands, digestive tract $[19,20]$.

The molality of solutions is defined by the proportion of amount of solution to mass of the dissolvent, and therefore, as distinct from the molality (proportion of amount of solution to the volume of the dissolvent) the molality of the solution does not changes with change of temperature. Simultaneous, variety of colors of substances in solutions points at necessarily of reference to the superposition principle of definition of osmotic pressures. With that, colligative traits of molality of solutions point at possibilities of usage of different technologies for definition of osmotic pressures. Four features from the colligative group are usually considered together and relate to the following phenomena:

1. Decreasing of pressure of a dissolvent spirit:

$$
\Delta \mathrm{P}_{\text {spirit }}=\mathrm{K}_{\text {spirit }} \mathrm{m},
$$

where $\mathrm{K}_{\text {spirit }}$ is a constant of the spirit pressure; $\mathrm{m}$ - molality.

2. Increasing of boiling temperature of solutions:

$$
\Delta \mathrm{T}_{\text {boil }}=\mathrm{Em},
$$

where $\mathrm{E}$ is an ebullioscopic constant;

3. Decreasing of freezing temperatures of solutions:

$$
\Delta \mathrm{T}_{\text {freeze }}=\mathrm{Km},
$$

where $\mathrm{K}$ is a cryoscopic constant.

4. Osmotic pressures

$$
\Delta \mathrm{P}_{\mathrm{osm}}=\mathrm{K}_{\mathrm{osm}} \mathrm{m},
$$

where $\mathrm{K}_{\mathrm{osm}}$ is a constant of the osmotic pressure.

As is clear from the abovementioned generalization, the specified features of substances are changing proportionally to the molality of solution. With that, those features do not depend on the nature and chemical composition of the solution, and every unit of the mentioned colligative characteristics can be measured, and on the basis of its values the other are calculated using the known formulas. 


\section{— Processes and Equipment of Food Productions -}

\section{Conclusion}

The analysis of special aspects of flowing of the material transformations in the anaerobic brew processes made on the basis of Gay-Lussac law allows to notice the following using the phenomenological considerations:

1. Summation of osmotic pressures of solutions of different substances shall be appropriately defined using the superposition principle.

2. Osmotic pressures of solutions of substances, that arise as a result of chemical and biochemical reactions, are proportional to the comparative coefficients of the corresponding formulas.

3. Changes of osmotic pressures before and after flowing of chemical and biochemical reactions are characterized by changes of quantity of molecular structures that are building up.

\section{References}

1. Wolfgang Kunze (2011), Technologie Brauer und Mälzer, LB Berlin, Berlin.

2. Natalia Tkachuk, Oleksandr Shevchenko (2016), Effects of osmotic pressure environments lethal effects on the level of microorganisms in the conditions of evacuation, Ukrainian Food Journal, 5(1), pp. 155-161.

3. Chaudhry Q., Castle P., Wathins R. (2010), Nanotechnology in food, RSC Publishing.

4. Burdo O.G. (2005), Nano-sized effects in the food technologies, Engineering and Physics Journal, 1, pp. 88-93.

5. Tippens Paul E. (2007), Physics. 7th ed, McGraw-Hill.

6. Monk Paul (2004), Physical Chemistry: Understanding our Chemical World, Wiley.

7. Atkins Peter, De Paula Julio (2006), Physical Chemistry (8th ed.), W.H. Freeman and Company.

8. Sokolenko A.I. (2011), Intensification of the heat and mass-transfer processes in the food technologies. Monography, Fenix, Kyiv.

9. Cooper Crystal (2010), Gay-Lussac's Law, Bright Hub Engineering, Available at: http://www.brighthubengineering.com/hvac/26213-gay-lussacs-law/

10. Shevchenko O.J. (2006), Scientific basis and hardware design of processes for longterm storage of food, NUFT, Kyiv.

11. Holtzer Alfred, Holtzer, Marilyn F. (2002), Use of the van't Hoff relation in determination of the enthalpy of micelle formation, The Journal of Physical Chemistry, 78(14), pp. 1442-1443.

12. Fernando Santos, Aluízio Borém and Celso Caldas (2015), Sugarcane. Agricultural Production, Bioenergy and Ethanol, Academic Press.

13. Stefan Hohmann (2002), Osmotic adaptation in yeast-control of the yeast osmolyte system, International Review of Cytology, 215, pp. 149-187

14. Anderson T.M. (2009), Industrial Fermentation Processes, Encyclopedia of Microbiology (Third Edition), pp. 349-361

15. Stewart G.G., Priest F.G. (2011), Food and Beverage Stability and Shelf Life, Woodhead Publishing

16. Piddubnyi V., Chagayda A., Boiko O. (2014), Adiabatic dynamina of cooling mashing through creation of vacuum in the fermentation apparatus, Journal of food and packaging science technique and technologies, 3(4), pp. 10-14. 
17. Chau C-F., Wu S-H., Yen G-C (2007), The development of regulations for food nanotechnology, Trends Food Sci. Technol., 18, pp. 269-280.

18. Chahaida A.O., Piddubnyi V.A., Maksymenko I.F., Boiko O.O. (2013), Intensyfikatsiia zbrodzhuvannia tsukrovmistnykh seredovyshch, Scientific works of National University of Food Technologies, 51, pp. 77-83.

19. Mansoor M. Amiji, Beverly J. Sandmann (2002), Applied Physical Pharmacy, McGraw-Hill Professional.

20. Bogomolov B.N. (2007), Bolshaia meditsinskaia entsiklopediia, AST, Moscow. 